\title{
The research of intelligent hydraulic disc brake for shear machine
}

\author{
Zhou xinjian, Qu Xiangchao \\ Institute of Mechanical Engineering, Xian University of Science and Technology, Xi' an, 710054, \\ China
}

email:2272690977@qq.com email:1055071635@qq.com

Keywords: hydraulic disc brake, intelligent test, shear machine

\begin{abstract}
Aiming at the existence of shear machine hydraulic brake disc friction pair wear quantity, temperature overrun problems couldn't be measured online, research and develop an online intelligent test system, test the temperature of friction pair and wear of hydraulic brake. This paper introduces the structure and composition of intelligent hydraulic brake disc displacement and temperature detection system and its function and testing process, etc. The system use PLC processor as the core, realize the on-line measurement of displacement and temperature and transfinite alarm function.
\end{abstract}

\section{Introduction}

Disc brake is the key component in the shear machine and other heavy machinery equipment,It has a simple structure,small volume, the brake torque big etc, the reliability of the performance for the stable operation of the shear machine and safety of operator is very important.Research and develop an online testing system for hydraulic disc brake,the on-line detection system uses temperature and displacement sensor for testing,achieve the friction material surface temperature and displacement on-line inspection and storage, when the temperature and the displacement out of range or friction material thermal fatigue strength exceed the limit,alarm ring.

\section{The problems existing in the hydraulic brake disc and solutions put forward}

Because of how much the friction plate wear directly affect the size of the brake torque.Temperature high and low directly affect the friction coefficient of friction pair, at the same time also may produce thermal fatigue.Brake offline testing has two obvious shortcomings:one is requiring stop detection, taking production hours; the other is the occur of the friction material suddenly damaged can not be detected during operation .If it can online detect the friction material wear and friction materials highest real-time temperature, according to the set limit value if exceed the set limit can determine the brake is in danger, the friction material needs to be replaced.Timely replacement of friction material, further improve the safety and reliability of brake, provide a powerful guarantee for maintenance.

With the development of coal enterprises in our country,the requirement of intelligence for coal winning machine is more and more high. So,research and develop an intelligent hydraulic brake for coal on-line detection of temperature and displacement is necessary.

\section{The structure of Intelligent disc brake}

The general structure of intelligent hydraulic brake disc including the mechanical part and testing part.

Mechanical part is similar with the structure on the graph,Only at the position B on the brake rear cover,process a hole to install displacement measurement sensor detecting friction wear.At the position $\mathrm{C}$ on the plate of brake, process the hole and slot to install temperature sensor, and uniform distribution 6 sensors.

Brake disc detection part, including the displacement sensor and temperature sensor, the hardware circuit and software control part.Hardware mainly collect all kinds of sensor 
signals,conversion and display,Software complete processing of detected information and control function.

\begin{tabular}{|c|c|}
\hline 1 & Friction plate \\
\hline 2 & Brake disk \\
\hline 3 & Oil inlet \\
\hline 4 & spring \\
\hline 5 & The positioning pin \\
\hline 6 & The brake release bolts \\
\hline 7 & Rear cover \\
\hline 8 & The piston \\
\hline 9,11 & Type $O$ sealing ring \\
\hline 10 & Cylinder block \\
\hline 12 & $\begin{array}{l}\text { Detection circuit } \\
\text { flame-proof shell }\end{array}$ \\
\hline A & Screw hole \\
\hline B & Displacem ent sensor \\
\hline E & Temperature sensor \\
\hline
\end{tabular}

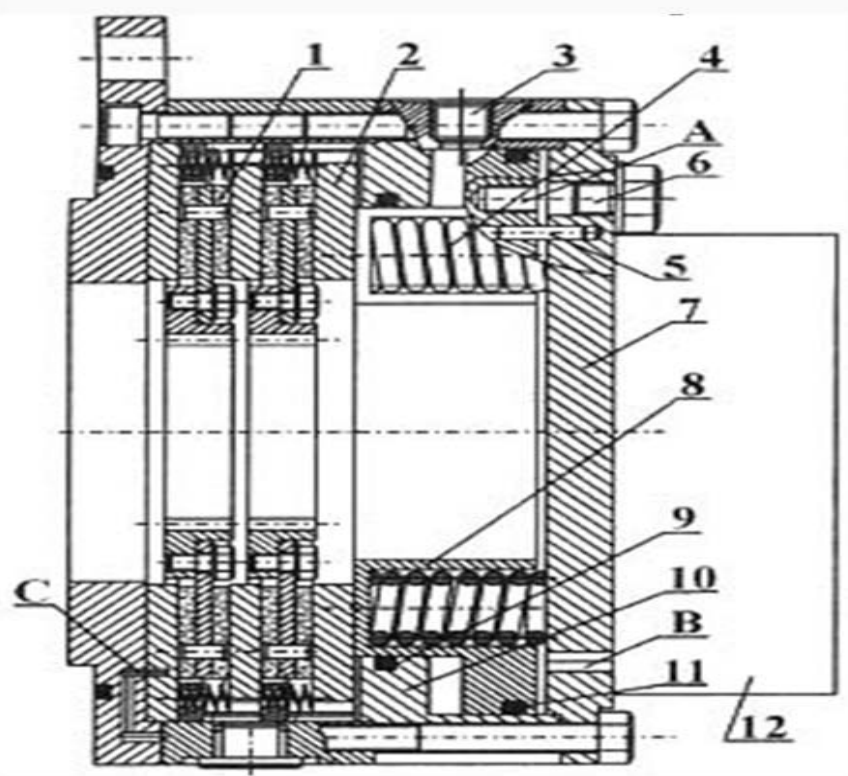

Figure 1 The structure of Intelligent disc brake

\section{Detecting system composition and function}

Detecting system consists of data acquisition part,A/D conversion circuit,PLC, the output display part and alarm parts. The system use PLC for data processing, the temperature sensor and displacement sensor to collect the signal,LED display and alarm.

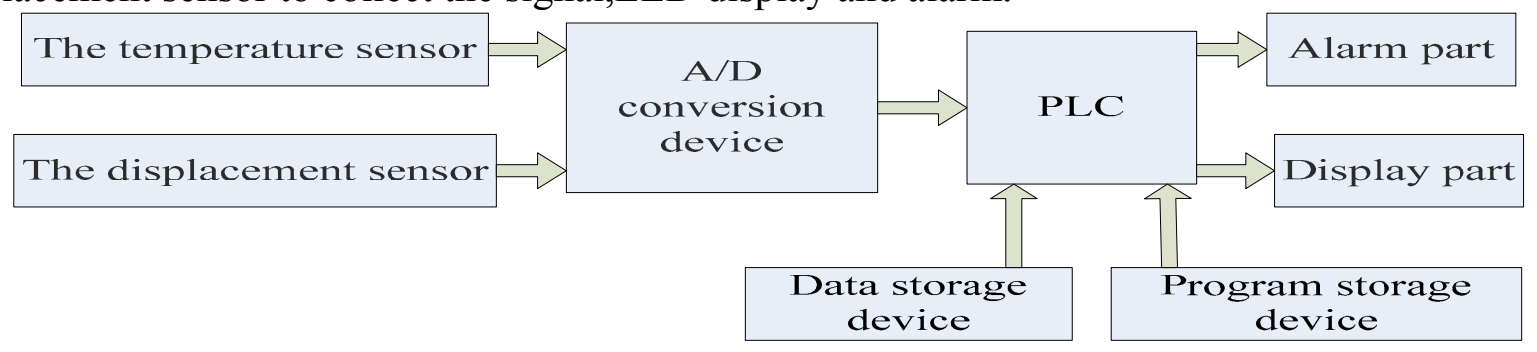

Figure 2 Consist of the detecting system

The temperature and displacement sensor collect the check point temperature and displacement parameters, convert into a digital signal after A/D conversion,put into PLC.PLC compare the detect data with the limit data of previously stored, if the data is in the limit data range represent security,display the detect data ;If the data is beyond the limit of data,represent not safety and put data into the alarm,issue a warning signal, suggesting the friction plate needs to be replaced. If the temperature within the limit temperature is repeated several times and the thermal fatigue generated more than material thermal fatigue limit, emit alarm signals.

\section{The temperature sensor}

The temperature sensor is the key element of temperature measurement in this system,Thermocouple is widely used at present and develop more perfect in temperature sensor.It is at many aspects correspond with the requirement of a kind of ideal temperature sensor:(1)Wide measuring range, the signal can be measured from $271 \mathrm{C}$ to $+2800 \mathrm{C}$ and temperature can be higher;(2)Stable performance and high accuracy;(3)Due to the thermocouple is voltage signal measured, so the signal can be long-distance transfer and record.In addition,the structure of thermocouple is simple,reaction fast, the temperature of the point can be measured by it .

\section{The displacement sensor}

This system choose non-contact measurement sensors,because of the eddy current sensor with measurement of wide linear range, high sensitivity, simple structure and not affected by oil and other media ,and other advantages,so it has been widely used. 


\section{The selection of PLC}

Using 2764 for the 8031 PLC external program memory and data memory expansion.using 8155 for I/O expansion of 8031 PLC, using 74LS138A decoder to select each chip , using 74LS373 as an address latch to latch issued address signal of $\mathrm{P} 0$ port .

Detecting system use the sensor for the multi-point temperature and displacement measurement on the brake.Using PLC to deal with data collected.Its main characteristic are : low cost, simple operation, high precision, wide measurement range,the main function achieved:(1) detect the real time temperature and wear of the test points to realize the online detection. (2) when the temperature and the displacement value is beyond the scope of measuring points, send out alarm signal.

\section{Data acquisition system}

The function of data acquisition system is through sensors using AD363 to convert detected temperature and displacement analog electrical signals into digital signals,input to the 8031 PLC for processing.AD363 is a full 16 channel composed of integrated circuit, 12 byte data acquisition system.It consists of two independent function modules,analog input module contains two 8 channel selection switch, differential amplifier, sample holder and address register and control logic. Analog-to-digital conversion module contains a 12 byte successive approximation A/D converter, the internal clock and comparator, buffer amplifier and so on.Its main characteristic is inside the module a single-ended or differential forms switch available for the user to control the selector.

\section{The software design and test process}

(1) It mainly use for hardware initializing and calling function of subroutine.

(2) Data acquisition and A/D conversion subroutine:According to the collection parameters for the corresponding analog signal sampling, quantification, and processing.And return corresponding signal values to the main program

(3) Display program: the main function is complete the symbols, numerical display and output.

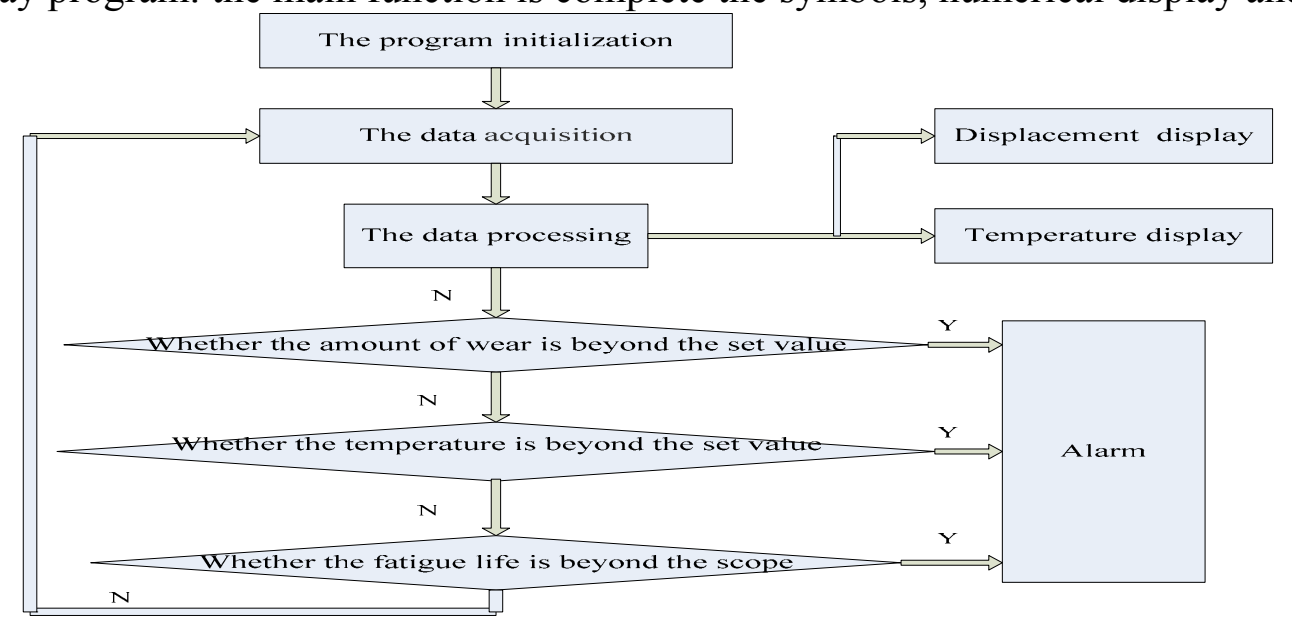

Figure 3 The software detecting process

\section{Conclusion}

(1) The successful development of on-line measuring hydraulic brake disc, solve the problem of long time replacement of friction material on the basis of experience, provide a more scientific basis for hydraulic brake disc replacement of friction material,effectively reduce the unnecessary waste of manpower and materials, reduce the security hidden danger, improve the reliability of equipment operation, has important application value.

(2) Work out detection scheme and sensor installation program.

(3) Design and complete the online intelligent detecting system, consist of PLC, temperature 
sensor, displacement sensor, A/D converter, memory device, display and alarm device and so on, using the system complete the friction temperature field and erosion rate real-time measure, and when friction plate temperature and wear out of the range, then send out alarm signal.

\section{References}

[1] Wang Li, Xu Xiaofeng, Xing Sihui, The Detecting Temperature System by Single Chip Computer[J] Cfhi Techonlogy, 1999(1)

[2] Liu mei, Zhang Weining, The application of MCS-51 single chip temperature in the detecting and controlling temperature system[J], Shandong Electronics, 1994(4)

[3] Zhou Xinjian, Chen Anning, Wang Xiaowei, Reformation of Hydraulic Disc-brake for shearers[J], Lubrication Engineering, 2003(1)

[4] Zhao Yan, Sensor Principle and Its Application[M],Peking University Press, 2009(10)

[5] Li Xun, CHMOS chip microcomputer principle and application[M],Beijing University of Aeronautics and Astronautics Press, 1991 : 2-59 